\title{
Research on How Ancient Traffic Affect National Sports Culture Development in Border Areas* ----A Case Study of Yunnan Province
}

\author{
TaoLin Huang, YunXian Li, LIPeng Wang, GuangYin Zhou and WeiDong Shen \\ Physical Education Department, Kunming University of Science and technology, Kunming 650500, China \\ 13388710989@163.com
}

\begin{abstract}
In this paper, on the basis of a comprehensive collection and compilation of relevant historical data, we make a careful research on the traffic situation between Yunnan and other places from Qin and Han Dynasties to Qing Dynasty, and focus on that of traffic lines and stagecoach settings in this region. With ancient traffic in Yunnan as a entry point, deeply analyze the formation of national sports culture in Yunnan, the natural and humane environment root in development, and then more fully understand the cultural exchanges between various ethnic groups.

Index Terms - Yunnan National sports National culture Ancient traffic
\end{abstract}

\section{Research purpose}

Yunnan is located in the southwest border of the motherland, the surrounding borders on multinational, and it is also the largest ethnic minority-populated provinces. 26 ethnic living in harmony in this land, gave birth to the colorful ethnic cultures. Yunnan is an important stopover for ASEAN to mainland, in the construction of bridgehead for the opening up in southwest China, how to promote culture in Yunnan to Go out and strengthen the exchange and cooperate with Southeast Asia and South Asia? How to introduce and promote national culture in Yunnan better? Writer tries to give relevant theoretical basis on strategy of province building by promote the construction of national culture, give relevant theoretical suggestion for culture to go out, with research on how ancient traffic affect national culture and national sports culture development as a entry point.

\section{Research method}

\section{A. literature methods}

Make this paper in reference to historical documents, and related information on the Internet

\section{B. Expert interview}

For a better understanding of the history of ancient traffic in our province, we interviewed with many relevant experts, scholars, teachers in Yunnan University, Yunnan Nationalities University and Yunnan Normal Universityand other colleges, which benefit us a lot.

\section{Field research method}

Field research also called fieldwork or field studies. In order to a better understanding of the ancient traffic conditions, we conducted a field study focused on the relevant historical sites.

\section{Results and analysis}

A history of traffic is an important side of overall process history. In every stage of historical development, we can trail the progress of traffic. Traffic conditions determine not only the size of cultural circles in history, but also affect the connections between various cultural circles, so communication of ancient culture and traffic conditions are inseparable. Whether material culture or spiritual culture will depend on traffic. Without the opening of silk road, grapes and carrots couldn't be brought to the Central Plains, without Columbus' discovery of the New World, Corns and potatoes couldn't become Eurasia foods. Similarly, without Monk Xuanzang travelling east and Monk Jianzhen Crossing the Ocean to Japan, a large number of Buddhist scriptures wouldn't spread from India to China and from China to Japan, and it would be impossible to penetrate into China for knowledge that of "the Consciousness-only " and " Hetuvidya". Therefore, it is closely related between development and progress of social history and traffic at any place. In this paper, on the basis of a comprehensive collection and compilation of relevant historical data, we make a careful research on the traffic situation between Yunnan and other places from Qin and Han Dynasties to Qing Dynasty, and focus on that of traffic lines and stagecoach settings in this region. With ancient traffic in Yunnan as a entry point, deeply analyze the formation of national sports culture in Yunnan, the natural and humane environment root in development, and then more fully understand the cultural exchanges between various ethnic groups.

\section{A. Overview of Ancient China Transportation}

In ancient times, our ancestors, evolving from apes learned to make tools. Then they began activities of transporting and information on purpose in the hunting life . The most primitive way of transportation is hand carrying, head lifting, burden bearing and shouldering, the most primitive way of transferring information is shouting and making gestures. At that time, with the development of social

\footnotetext{
* This work is partially supported :From 2012 Yunnan Education Science Science Planning Project topic (Y12026) support
} 
productive forces, the division of animal husbandry and agriculture appeared and started the exchange of products, which resulting in a small amount of local transportation. Later, the division of handicraft and agriculture appeared and money arose. With exchange of commodities increasing rapidly, the scope and number of transport are correspondingly expanding and increasing. Social division of labor is getting fine, and gradually formed transportation specialized in the transport of passengers and goods and postal service specialized in delivery of information. When the traffic become a relatively independent profession, with the development of social productivity and scientific and technological progress, the content and style of the ancient transport, post and telecommunications continues to develop and enrich. In the long course of human history, it experienced about several thousand years fro transportation changing from ancient human drag to today's air transport.

\section{B. Its special geographical position of Yunnan affect on ethnic culture of Yunnan and Yunnan Nationalities Physical Culture}

Yunnan has a special geographical location, as well as a special location as the three major cultural interchanges in East Asia, Southeast Asia and South Asia, which creates spatial distribution pattern of national culture, having a complex composition of Yunnan ethnic and cultures of various types. Culture of Yunnan has its unique complexity. And in eastern and central Yunnan, the unique feature is not in differences between its own unique culture and surrounding cultural, but rather that it is a cultural system with high degree of integration and heritage of many northern cultures. Such a unique fusion can be obtained from the local language, ethnic clothing, food, architectural style, and even some of the large family tree. Northern area mainly refers to earlier Han cultural areas, such as Shandong, Henan, Hebei, Shaanxi, northeastern southwestern and southeastern Northwest area, such convergence is a "enclave" type of the northern culture spread across south. this cultural uniqueness of Yunnan has a certain value in research on geographical relevance of traditional culture and cultural heritage.

From the Warring States to feudal society, then to the Western Han, the foundation of the feudal system in Central Plains has become more stable. While "Dian country" as the representative of Yunnan culture is still in the period of slavery. According to propagation law that culture flows from high to low, the trends of culture spread, including sports culture is inevitable. Yunnan ancient sports affected by Central Plains cultural has little difference from Central Plains cultural in chronological order of the content's performance. For example, in the Western Han Dynasty, wrestling attributed to "one hundred play" has been developed to an advanced stage of human to human. The Yunnan still remains a barbarous and low level stage. At that time, people fight against beast, which once prevailed in the Central Plains as well, outdated temple dance still prevailed in the "Dian", which is determined by the objectivity of social process with time difference.
C. The main channel of ancient Yunnan affect on Yunnan Ethnic Culture

a) "WuChi road" The main channel of ancient Yunnan affect on Yunnan Ethnic Culture

During almost 500 years of" Dian" history ,there have been 3 large events related to culture exchanges: First, go into Yunnan through Zhuang Qiao in the late Warring States, followed by opening up of "five feet" and setting of offices in Qin Dynasty, later, when Emperor Wu of Han connected to "Southwest" and set counties. Five feet is the oldest state highway, which connected Yunnan with the mainland. In 246 BC, Emperor Qin Shi Huang start to develop and govern Yunnan through road construction. Li Bing, Prefecture in Shu County, lead to dig the cliffs at the junction of Sichuan and Yunnan Bo Road (now Sichuan Yibin), try to build roads leading to the area in the northeast of Yunnan. After Emperor Qin Shi Huang unified China, he appointed Chang An to continue building this road. Five feet starts from Bo Road in the south of Shu County(now Sichuan Yibin), Zhuti (now Zhaotong in Yunnan) to the Dianchi Lake. As the roads are only five feet wide, it is known as "five feet" Road. Despite this narrow road, it has equal important significance as the emperor's wide fifty paces of the "Chi Road" built in the rest of the country.

\section{b) "Tea Horse road" The main commercial channel of Yunnan affect on Yunnan Ethnic Culture}

On 4,000 kilometers winding trail, it exists Palm- leaf culture of Xishuangbanna nationality, fire culture on the altar of Yi nationality and fire culture of Bai nationalit, Dongba culture of Naxi nationality, Tibetan snow culture. Various ethnic cultures blend on this trail, endlessly. Tea Horse Road in Yunnan has decisive significance in national culture, in a sense, without the Tea Horse Road, Yunnan ethnic culture would probably not be so rich, or not so rich.

\section{c) Southern Silk Road" The main commercial channel of Yunnan affect on Yunnan Ethnic Culture}

The existence of Southern Silk Road played a role as a bridge for both economic and cultural communication between China and Western countries. In the Central Plains, Zhang Qian is the person who firstly discovered the Silk Road. Southern Silk Road is a ancient international road passing through from Sichuan to Yunnan province, connecting Burma, India, leading to Southeast Asia, West Asia, and Europe countries. It together with the Northwest Silk Road and ancient maritime Silk Road is a main channel for China's outbound traffic with trade and cultural exchanges.

\section{d) Other main commercial channel of Yunnan affect on Yunnan Ethnic Culture}

In the period of "Nanzhao" country, due to positive operation in Yunnan frontier by Nanzhao governors, "South Sea" Road become transportation arteries contacting IndoChina region.

During Yuan Dynasty, since the opening of Bonanshan 
Road and Jiaozhou road, in a long period of time, these two roads are main channels for feudal dynasty to operate in Yunnan and Indochina

Ming and Qing dynasty period Transit of Ming Dynasty and Qing Dynasty in Yunnan has two characteristics. First, the administration of local road become more perfect, the second is the addition of some inns. A lot of people moved into Yunnan from inland, through this well protected channel, which promote local economic and social progress, and also laid a solid foundation for the development of modern Yunnan.

\section{Conclusions and suggestions}

\section{A. Conclusions}

The differences between culture at home and abroad, encourage people to get rid of ideological bourne, transform mind-set accumulated by experience and constantly enrich and develop themselves with foreign cultures and make their own culture to a new level. In a highly developed social network of modern information technology, cultural spread and impact is becoming faster and more simple. We can enjoy a wonderful synchronized NBA game at home. Many players become household worship idols. Exciting games and huge market value stimulate people's nerves. Modern sports spread its unparalleled impact rapidly. In this circumstance, development of traditional sports, which is a vulnerable culture, has been under a huge impact. Much valuable cultural wealth is dead or dying, it becomes a moral imperative of contemporary sports workers to protect and save this cultural heritage.

\section{B. Suggestions}

a) Give full play to its advantages in resources, accelerate the development of cultural industries, and form a culture of Yunnan characteristics of industrial clusters.

b) Yunnan as bridgehead in the construction of opening up southwest China, how to promote the culture of "going out", strengthen measures of cooperation and exchanges with Southeast Asia, South Asia.

First, give full play to the role of cultural diplomacy which means fully rely on Yunnan's regional advantages adjacent to Southeast Asia, South Asia and cultural advantage with cross-border neighbors, same root culture, the people's friendship for generations and a long cultural history. Fully embody the role of cultural ties and bridge, Yunnan's convenience and superiority in cultural exchanges and cooperation, further promote overall opening up and cooperation with Southeast Asia and South Asian countries, deeply implement country's foreign policy of " being a good neighbor and partner " and " creating an amicable, secure and prosperous neighborhood ". Second, give full play to the role of cultural propaganda, fully demonstrate four cards of Yunnan to Southeast Asia and South Asia, which is "eco Yunnan", "open Yunnan", "cultural Yunnan" and "Developing Yunnan", introduce and promote comprehensively and promote Yunnan's pace of opening to the outside world. Last, expand the spread of culture surface and influence in Yunnan, namely, strengthening published translations and promotional efforts of cultural products such as film and television, strengthen regional international contacts and exchanges between folk culture and art activities, enhance international academic exchanges and regional seminars and other cultures.

\section{References}

[1] Rao Yuan Year of 2005 Yunnan Nationalities Sports. Yunnan Nationalities Publishing House

[2] Fang Zhen Year of 2004 Analysis on Development Trend of National Traditional Sports. Journal of Yunnan Nationalities University: Philosophy and social sciences

[3] Liu Pengwei 5 period in 2005 On a regional national sports culture in Yunnan. Success(Education)

[4] Tan Zhili Year of 2006 Research on Traditional Sports Heritage, Evolution and Development of The migration of Yunnan Mongolian Yunnan Normal University

[5] Editorial office of Chinese highway history Year of 1985 A Brief History of Ancient Chinese road

[6] Yang Dehua Year of 1998 A Brief History of Yunnan Ethnic Relations Yunnan University Press

[7] Li Xiaohua Year of 2001 The impact of Central Plains culture in early feudal society on Yunnan Sports. Journal of Physical Education

[8] State Ethnic Affairs Commission Year of 2008 A brief history of the Hani Nationalities Publishing House

[9] Zhou Tingxian Year of 2007 Research on Yunnan Ethnic History [M] Yunnan Nationalities Publishing House. 